\title{
Ectopic pregnancy an obstetric emergency: retrospective study from medical college Ambala, Haryana, India
}

\author{
Shweta Tomar $\operatorname{Yadav}^{1}$, Simmanjit Kaur ${ }^{2}$, Sachin Singh Yadav ${ }^{3}$
}

\begin{abstract}
${ }^{1}$ Department of Obstetrics and Gynaecology, Teerthankar Mahaveer Medical College and Research center, Moradabad, Uttar Pradesh, India

${ }^{2}$ Department of Obstetrics and Gynaecology, M. M. Institute of Medical Sciences and Research, Mullana, Ambala, Haryana, India

${ }^{3}$ Department of Community Medicine, Teerthankar Mahaveer Medical College and Research center, Moradabad, Uttar Pradesh, India
\end{abstract}

Received: 29 April 2016

Accepted: 02 June 2016

\section{*Correspondence:}

Dr. Shweta Tomar Yadav,

E-mail: shweta.6279@gmail.com

Copyright: (c) the author(s), publisher and licensee Medip Academy. This is an open-access article distributed under the terms of the Creative Commons Attribution Non-Commercial License, which permits unrestricted non-commercial use, distribution, and reproduction in any medium, provided the original work is properly cited.

\section{ABSTRACT}

Background: Ectopic pregnancy remains the leading cause of maternal death in early pregnancy, the overall incidence of ectopic pregnancy is increasing but with improved diagnostic techniques and conservative management, case fatality rate has reduced. This study was undertaken to evaluate the incidence, clinical profile, associated risk factors, management and outcome of cases diagnosed as ectopic pregnancy.

Methods: This retrospective study was conducted at MMIMSR Mullana, Ambala from $1^{\text {st }}$ January 2014 to 31 December 2015. All women admitted with ectopic pregnancy in the gynae department were taken in the study.

Results: The incidence of ectopic pregnancy in our institute was $0.97 \%$, mainly affecting young multiparous women, out of 36 cases $15(41.7 \%)$ patients had risk factors previous abortion was commonest (19.4\%), followed by history of infertility, tubal ligation, ectopic pregnancy, $\mathrm{Cu} \mathrm{T}$ insertion. Acute abdominal pain was the commonest (94.4\%) symptom $2 / 3$ patients had tachycardia and abdominal tenderness, 10 were in shock. mild to moderate anemia present, while $17 \%$ severely anemic, urine pregnancy test was positive in all. 5 hemodynamically stable patients given single dose intramuscular methotrexate, surgical intervention in 31 cases by either laparoscopy or laparotomy, laparoscopy in 4 patients, 1 had to be converted to laparotomy. Fallopian tubes were commonest site; Ampulla was the commonest site in tubal rupture.

Conclusions: The ectopic pregnancy remains a public health issue. Timely diagnosis and transfer to higher center in hemodynamically stable state along with the use of conservative surgery or medical management can reduce morbidity and mortality.

Keywords: Ectopic pregnancy, Infertility, Methotrexate. Laparoscopy, Laparotomy

\section{INTRODUCTION}

Ectopic pregnancy is implantation of fertilized ovum any site other than uterine cavity. ${ }^{1}$ Fallopian tube is the commonest site. ${ }^{2}$ Ectopic pregnancy remains the leading cause of maternal death in early pregnancy. ${ }^{3}$ The associated risk factors are pelvic inflammatory disease, previous history of ectopic pregnancy, tubal ligation, intrauterine contraceptive devices, sexually transmitted diseases, infertility, ART. ${ }^{4}$ There is considerable regional variation in its incidence and globally, Worldwide, ectopic pregnancy complicates $0.25-2.0 \%$ of all pregnancies. ${ }^{5}$ Its incidence is increasing and has been risen from $4.9 / 1000$ pregnancies in 1970 to $9.6 / 1000$ 
pregnancies. ${ }^{6}$ The overall incidence of ectopic pregnancy is increasing in past three decades but with improved diagnostic techniques and conservative management, case fatality rate has reduced.

Any woman of reproductive age presenting with abdominal pain, vaginal bleeding, syncope, or hypotension with or without amenorrhoea with pregnancy test positive should be provisionally diagnosed as an ectopic pregnancy unless proved otherwise. Key to the diagnosis is presence or absence of intrauterine gestational sac correlated with serum B hCG levels. Management of case depends on clinical presentation, site of ectopic, and need for future reproductive function; management can be medical or surgical.

Importance of ectopic pregnancy is peculiar in our country because rather than join the global trend of early diagnosis and conservative approach in management we are challenged by late presentation and rupture in most cases. ${ }^{7}$ This retrospective study was undertaken to evaluate the incidence, clinical profile, associated risk factors, management and outcome of cases diagnosed as ectopic pregnancy in our medical college over last 2 years.

\section{METHODS}

This retrospective study was conducted at MMIMSR Mullana, Ambala from $1^{\text {st }}$ January 2014 to 31 December 2015. All women admitted with ectopic pregnancy in the gynae department via OPD or emergency were taken in the study. These cases were traced through the registers kept in gynae wards, and OT. The labour register was used to determine the number of deliveries during the study period. Each patient's data was obtained from their case records kept in medical records department. Data were collected in a preconceived format

The data obtained was entered in MS excel sheet and tabulated.

\section{RESULTS}

Total number of deliveries in our MMIMSR during study period were 4315, 42 patients were admitted with diagnosis of ectopic pregnancy but detailed analysis of data was done for 36 cases 6 patients were not included in the study due to incomplete data retrieval.

The incidence of ectopic pregnancy in our institute was $0.97 \%$, as depicted in (Figure 1) the major toll of ectopic pregnancy was over younger patients. Multiparous women were found to be more prone to have ectopic pregnancy $(61.1 \%)$ although $19.4 \%$ primigravidae were affected. Most cases presented at less than 8 weeks gestational age 1 patient did not had history of preceding amenorrhea. (Table 1) depicts that among 36 cases only $15(41.7 \%)$ patients had risk factors out of that previous abortion was commonest (19.4\%), 5 (13.9\%) had history of infertility 2 cases had history of tubal ligation, history previous ectopic pregnancy and $\mathrm{Cu} \mathrm{T}$ insertion was present in 1 case each.

Table 1: Risk factors.

\begin{tabular}{|lll|}
\hline Risk factors & No. of cases & percentage \\
\hline Abortion & 7 & 19.4 \\
\hline Infertility & 5 & 13.9 \\
\hline Tubal ligation & 2 & 5.5 \\
\hline Ectopic pregnancy & 1 & 2.8 \\
\hline $\mathrm{Cu} \mathrm{T}$ & 1 & 2.8 \\
\hline
\end{tabular}

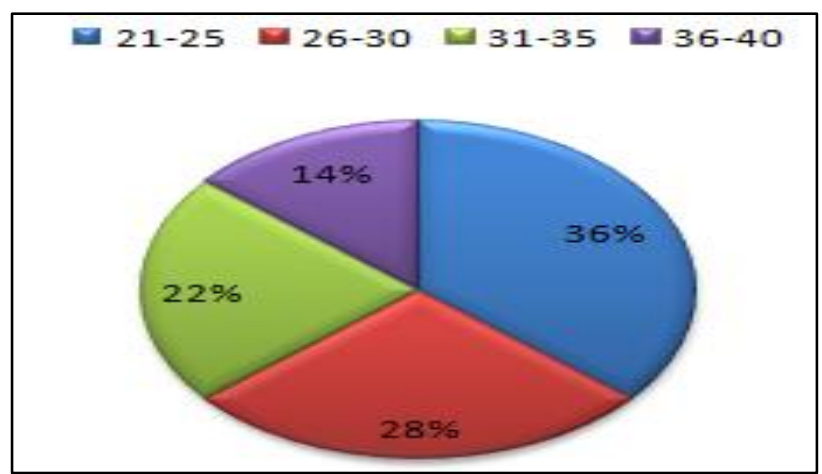

Figure 1: Age distribution.

Acute abdominal pain was the commonest (94.4\%) symptom followed by bleeding per vaginum, nausea, syncope were less frequently observed. 1 patient was asymptomatic and diagnosed on routine antenatal USG. Almost 2/3 patients had tachycardia and abdominal tenderness, 10 patients came in shock. 1 was incidental finding. Cervical movement and forniceal tenderness was observed in almost $40 \%$ cases (Table 2).

Table 2: Clinical presentation.

\begin{tabular}{|lll|}
\hline Symptom/sign & Present $(\%)$ & Absent $(\%)$ \\
\hline Pain Abdomen & $34(94.4 \%)$ & $2(5.6 \%)$ \\
\hline Bleeding P/V & $26(72.2 \%)$ & $10(27.8 \%)$ \\
\hline Nausea & $12(33.3 \%)$ & $24(66.7 \%)$ \\
\hline Syncope & $9(25 \%)$ & $27(75 \%)$ \\
\hline Tachycardia & $24(66.7 \%)$ & $12(33.3 \%)$ \\
\hline Abdominal tenderness & $25(69.4 \%)$ & $11(20.6 \%)$ \\
\hline $\begin{array}{l}\text { Cervical movement and/ } \\
\text { forniceal tenderness }\end{array}$ & $15(41.7 \%)$ & $21(60.3 \%)$ \\
\hline Shock & $10(25 \%)$ & $26(75 \%)$ \\
\hline
\end{tabular}

Most cases had mild to moderate anemia, while $17 \%$ cases were severely anemic (Figure 2), urine pregnancy test was positive in almost all cases but in 10 cases it was weakly positive, serum beta hCG was not done in all cases due to financial restraints. 13 patients had adnexal mass on TVS while hemoperitoneum was evident on 29 cases and 7 patients had evidence of both hemoperitoneum and adnexal mass. 
5 cases who were hemodynamically stable and had adnexal mass $<3 \mathrm{~cm}$ without evidence of free fluid on ultrasound, after well informed consent opted for medical treatment with single dose intramuscular methotrexate 50 $\mathrm{mg} / \mathrm{m}^{2}$. $80 \%$ case selected for medical management responded successfully and had complete resolution of ectopic gestation, while 1 patient reported in emergency with acute pain abdomen on day 14 of methotrexate administration and laparotomy had to be performed for that in view of rupture ectopic. Remaining 31 cases planned for surgical intervention by either laparoscopy or laparotomy under suitable anesthesia, laparoscopy was attempted in 4 patients out of which 1 had to be converted to laparotomy due to dense adhesions and difficult entry (Table 3).

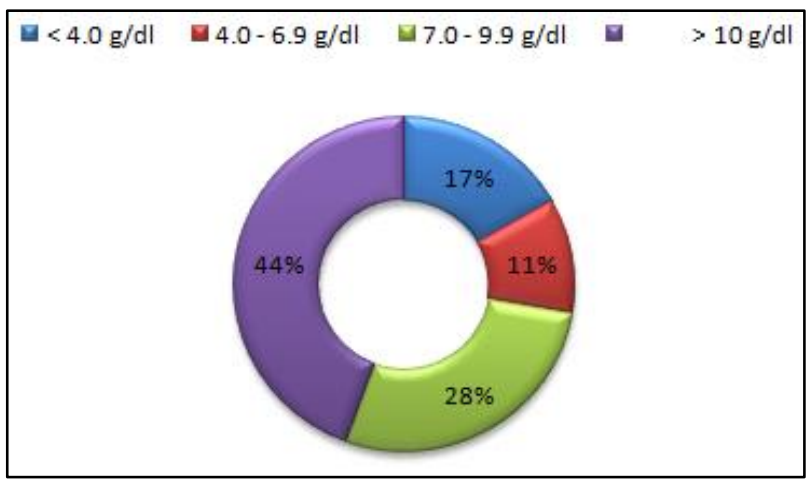

Figure 2: Haemoglobin.

Table 3: Management.

\begin{tabular}{|ll|}
\hline Management & Number \\
\hline Conservative & 5 \\
\hline Successful & 4 \\
\hline unsuccessful (emergency laparotomy) & 1 \\
\hline Surgical & 31 \\
\hline Laparoscopy & 3 \\
\hline Laproscopy converted to laprotomy & 1 \\
\hline Laparotomy & 26 \\
\hline
\end{tabular}

\section{Intraoperative findings}

Mild to moderate hemoperitoneum was present in 25 patients, while massive hemoperitoneum was in 3 cases. Fallopian tubes were commonest site, ovarian and cornual pregnancy was found in 1 patient each. Tubal abortion was evident in 3 cases. Ampulla was the commonest site in tubal rupture followed by isthemic region.

28 patients needed blood transfusion in intraoperative or postoperative period. 7 needed more than 2 units of blood. There was no mortality attributed to ectopic pregnancy. 9 cases had febrile illness in postoperative period, 7 had wound infection out of them 2 needed resuturing due to gapped wound.

\section{DISCUSSION}

The incidence of ectopic pregnancy in our institute was $0.097 \%$, which was similar to different studies done earlier in India, (Table 4).

Table 4: Incidence reported earlier.

\begin{tabular}{|llc|}
\hline Authors & Incidence of ectopic & Year \\
\hline $\begin{array}{l}\text { Gaddagi RA, } \\
\text { Chandrashekhar AP }\end{array}$ & $1: 285$ deliveries. & 2012 \\
\hline Tuli AG et al $^{7}$ & $1.66 \%$. & 2015 \\
\hline $\begin{array}{l}\text { Prasanna B, Jhansi CB, } \\
\text { Swathi K, Shaik MV }\end{array}$ & $1.8 \%$ & 2016 \\
\hline Wakankar R, Kedar K & $1.99 \%$ & 2015 \\
\hline $\begin{array}{l}\text { Thonneau P, Hijazi Y, } \\
\text { Goyaux N, Calvez T, } \\
\text { Keita N }\end{array}$ & $0.25-2.0 \%$ & 2002 \\
\hline Our study & $0.97 \%$, & 2016 \\
\hline
\end{tabular}

As reported by earlier researchers our majority of our study patients were $<30$ years age most of the women in India marry at an early age and completes their family at an early age. ${ }^{4,7,8}$ This age corresponds to the age of peak sexual activity and reproduction. According to our study multiparous women were found to be more prone to have ectopic pregnancy (61.1\%) although $19.4 \%$ primigravidae were affected. This observation supports earlier results on the contrary Some studies are showing increased risk of ectopic pregnancy in nulliparous or primiparous. ${ }^{4,8,10,11}$

No risk factor was found in $19(58.3 \%)$ patients. Earlier study report PID as the most common risk factor we found previous abortion was commonest (19.4\%) irrespective of the fact whether it is induced or spontaneous, this disparity may be due to mild to moderate episodes of PID which in most cases went unrecognised. ${ }^{7,10}$ Prasanna B et al reported history of previous abortion/ dilatation and curettage (D and C) in $16 \%$, the relationship between prior abortions and ectopic pregnancy is explained by the post-abortal infections leading to tubal damage. ${ }^{4}$ Among our patient a history of infertility was present in $13.9 \%$, which is correlating with the studies done by Panchal D, et al. $(11.66 \%)$ and Tuli AG (12.98\%) the association between infertility, previous pelvic infection and tubal pathology is the possible explanation. ${ }^{7,13}$

The incidence of ectopic pregnancy following infertility treatment is much higher as compared to spontaneous pregnancies. Tuli AG reported history of infertility treatment in $12.98 \%$ which is corroborated by our study $(13.9 \%)$. There is $15-50 \%$ chance of being ectopic if pregnancy occurs following tubal surgeries. ${ }^{71} 2(5.5 \%)$ cases had history of tubal ligation, history previous ectopic pregnancy $\mathrm{Cu} \mathrm{T}$ insertion was present in $1(2.7 \%)$ case each. Rashmi A (2.7\%) reported similar incidence of 
previous ectopic pregnancy on the contrary Tuli AG found higher $(9.09 \%)$ Incidence. ${ }^{7,8}$

The classical findings of pain in the abdomen, amenorrhoea and vaginal bleeding are not seen in all the cases. Most cases presented at less than 8 weeks gestational age 1 patient did not had history of preceding amenorrhea. Acute abdominal pain was the commonest (94.4\%) symptom followed by bleeding per vaginum, nausea, syncope was less frequently observed. This is correlating with the study done by Gupta $\mathrm{R}$, et al and Prasanna B et al. ${ }^{4,15}$ Almost 2/3 patients had tachycardia and abdominal tenderness, 1 was incidental USG finding. Cervical movement and forniceal tenderness was observed in almost $40 \%$ cases. According to the National Family health survey III (2005-2006), the prevalence of anemia in India is $57.9 \%$. Preexisting anemia with superimposed acute blood loss explains the higher incidence of pallor in ruptured ectopic pregnancy. Among our study most cases had mild to moderate anemia, while $13.9 \%$ cases were severely anemic which is similar to earlier studies out 36 patients came in shock. Which is slightly higher than reported by Panchal D, et al. ${ }^{4,8,10,13}$

urine pregnancy test was positive in almost all cases but in 10 cases it was weakly positive which correlated with the study done by Rashmi A Gaddagi, et al. (97.3\%) and W.M. Fageeh (96\%). ${ }^{8,17} 13$ patients had adnexal mass on TVS while hemoperitoneum was evident on 29 cases and 7 patients had evidence of both hemoperitoneum and adnexal mass. While Prasanna B reported evidence of rupture in 41 patients and 9 were diagnosed as unruptured ectopic. $^{4}$

For women who present early with ectopic pregnancy laparoscopy and medical management with methotrexate remains an attractive option as was seen in our study and by Olofsson et al. ${ }^{17} 5$ cases who were hemodynamically stable and had adnexal mass $<3 \mathrm{~cm}$ without evidence of free fluid on ultrasound, after well informed consent opted for medical treatment with single dose intramuscular methotrexate $50 \mathrm{mg} / \mathrm{m}^{2} .80 \%$ case selected for medical management responded successfully and had complete resolution of ectopic gestation, while 1 patient reported in emergency with acute pain abdomen on day 14 of methotrexate administration and laparotomy had to be performed for that in view of rupture ectopic. Remaining 31 cases planned for surgical intervention by either laparoscopy or laparotomy under suitable anesthesia, laparoscopy was attempted in 4 patients out of which 1 had to be converted to laparotomy due to dense adhesions and difficult entry.

Tubal ectopic were commonest, ovarian and cornual pregnancy was found in 1 patient each. Tubal abortion was evident in 3 cases. Ampulla was the commonest site in tubal rupture followed by isthemic region in our study correlating with other studies. ${ }^{7-10}$
Among our 36 patients, 28 (77.8\%) patients needed blood transfusion in intra operative or post-operative period. 7 needed more than 2 units of blood. There was no mortality attributed to ectopic pregnancy. 9 cases had febrile illness in postoperative period, 7 had wound infection out of them 2 needed re suturing due to gapped wound. Wakankar $\mathrm{R}$, reported Blood transfusion $(\geq 2$ pints) in $30(57.69 \%)$ out of 52 cases. ${ }^{9} 11$ patients required more than 10 days postoperative hospital stay. Among 5 patients with wound complication, 2 cases had burst abdomen, and 3 had wound gape.

\section{CONCLUSION}

The ectopic pregnancy remains a public health issue. In order to reduce morbidity there is need of early diagnosis. Timely diagnosis and transfer to higher center in hemodynamically stable state along with the use of minimal access surgery or medical management can revolutionize the scenario of ectopic pregnancy in the developing world and at same time safeguard the prospective for future fertility.

\section{Funding: No funding sources \\ Conflict of interest: None declared \\ Ethical approval: Not required}

\section{REFERENCES}

1. Farquhar CM: Ectopic pregnancy. Lancet. 2005;366(9485):583-91.

2. Sivalingam VN, Duncan WC, Kirk E, Shephard LA, Horne AW. Diagnosis and management of ectopic pregnancy. J Fam Plann Reprod Health Care. 2011;37(4):231-40.

3. Department of Health. In: Drife J, Lewis G, editors. Why Mothers Die:A Confidential Enquiry in to the Maternal Deaths in the United Kingdom. Norwich, UK: HMSO; 2001:282.

4. Prasanna B, Jhansi CB, Swathi K, Shaik MV. A study on risk factors and clinical presentation of ectopic pregnancy in women attending a tertiary care centre. IAIM. 2016;3(1):90-6.

5. Thonneau P, Hijazi Y, Goyaux N, Calvez T, Keita N. Ectopic pregnancy in Conakry, Guinea. Bull World Health Organ. 2002;80:365-70.

6. Royal college of London. Obstctritians and Gynaecologisls. Guideline No. 21 on the Management of Tubal Pregnancies. London: RCOG; 1999.

7. Tuli AG, Goyal S, Livingston D, Kurian AS. Ectopic pregnancy: a five year retrospective study in a tertiary care hospital. Int J Reprod Contracept Obstet Gynecol. 2015;4:1400-3.

8. Gaddagi RA, Chandrashekha AP. rA clinical study of ectopic pregnancy. Journal of Clinical and Diagnostic Research. 2012;6(5):867-9.

9. Wakankar R, Kedar K. Ectopic pregnancy-rising trend at Indira Gandhi Government Medical College, Nagpur. Int J Sci Stud. 2015;3(5):18-22. 
10. Sujata P, Pati BK, Sahoo G. Ectopic pregnancy-a five year review. Indian Journal of Perinatology and Reproductive Biology. 2014;04(2):21-4.

11. Majhi AK, Roy N, Karmakar KS, Banerjee PK. Ectopic pregnancy-an analysis of 180 cases. J Indian Med Assoc. 2007;105:308-12.

12. Igwegbe AO, Eleje GU, Okpola BC. An appraisal of the management of ectopic pregnancy in a Nigerian Tertiary Hospital. Ann Med Health Science Res. 2013;3(2):166-70.

13. Panchal D, Vaishnav G, Solanki K. Study of management in patient with ectopic pregnancy. National Journal of Integrated Research in Medicine. 2011;2(3):91-4.

14. Dutta DC, Haemorrhage in early pregnancy. In: Koner H, editor. Textbook of Obstetrics. Revised reprint of $7^{\text {th }}$ edition; 2013:177-190.
15. Gupta R, Porwal S, Swarnkar M, Sharma N, Maheshwari P. Incidence, trends and risk factors for ectopic pregnancies in a tertiary care hospital of Rajasthan. J Pharm Biomed Sci. 2012;16(7):1-3.

16. Fageeh WM. Diagnosis and management of ectopic pregnancy in king abdulaziz university hospital: a four year experience. JKAU. Med Sci. 2008;15(2):15-25.

17. Olofsson JI, Poromaa IS, Ottander U, Kjellberg L, Damber MG. Clinical and pregnancy outcome following ectopic pregnancy; a prospective study comparing expectancy, surgery and systemic methotrexate treatment. Acta Obstet Gynaecol Scand. 2001;80(8):744-9.

Cite this article as: Yadav ST, Kaur S, Yadav SS Ectopic pregnancy an obstetric emergency: retrospective study from medical college Ambala, Haryana, India. Int J Reprod Contracept Obstet Gynecol 2016;5:2210-4. 